\title{
Factors Influencing Fashion Adoption among the Youth in Johannesburg, South Africa
}

\author{
*Marike Venter, Richard Chinomona, Tinashe Chuchu \\ University of the Witwatersrand, Johannesburg, South Africa \\ *Marike.venter@wits.ac.za, Richard.chinomona@wits.ac.za, tinashe.chuchu@wits.ac.za
}

\begin{abstract}
Fashion in Africa has undergone a tremendous transformation process due to an increase in international trade. As a result, African consumerism has surfaced. Through being part of the global community, the youth in Africa capitalizes on the wide variety of fashions available, and they view fashion as a medium for expressing their identity. More specifically, in South Africa, fashion is used as the ideal vehicle for the youth to re-map previously fixed racial identities. Although a number of studies have explored this subject in an array of contexts, limited research has focused on factors that drive fashion adoption among the youth in Johannesburg. In view of this identified research gap, the present study aims to investigate the impact of fashion consciousness, the need for uniqueness, interpersonal influence, individualism/collectivism, and masculinity/femininity on fashion adoption. A Field study was conducted in Johannesburg and research data were collected from 400 respondents aged between 18 to 29 years. Linear regression analysis was performed to explore the relationship between the quantitative outcome variable and the predictor variables of the study by use of the SPSS 22 and the AMOS 22 software program. The results reveal that two of the five variables positively influence fashion adoption, while individualism/collectivism has an inverse relationship with fashion adoption. The significance of gaining insight into such factors, draw from the rich political history of South Africa and how the youth's conflicting identities may influence the modern concept of adopting global fashion trends.
\end{abstract}

Keywords: Style, youth, fashion adoption, Generation $Y$, South Africa

\section{Introduction}

Fashion adoption has been a major topic of discussion in fashion literature over the past few decades (Beaudoin, Moore \& Goldsmith, 2000; Johnson, Lennon, Jasper, Damhorst \& Lakner, 2003; Rahman, Saleem, Akhtar, Ali \& Khan, 2014). This is largely due to the rapidly growing fashion industry. In fact, emerging markets account for almost $40 \%$ of the women's apparel today and it is expected to rise above $50 \%$ by 2025 (Keller, Magnus, Hedrich, Nava \& Tochtermann, 2014). Furthermore, fashion is amongst the sectors that gains the most from global trade liberalization, and provides job opportunities for unskilled labour, especially in emerging markets (Nordas, 2003). In Africa, fashion has undergone a transformation process, following European colonization and an increase in international trade, and as a result African consumerism has surfaced (Jewsiewicki, 2008). Through fashion, the youth express their identity, and use style as a communication tool of individual identities (Singh, 2011). Fashion adoption is not a new phenomenon and as a result has been explored in several studies. A common theme that is often found in fashion adoption literature is studies on fashion innovativeness. For example, Jun and Rhee (2009) conducted a study that investigated the effects of fashion innovativeness and style-innovation attributes on fashion adoption among females in Korea. Another study that was conducted by Jun \& Rhee (2009) investigated the effect of fashion innovativeness level on fashion adoption. Furthermore, Rahman et al. (2014) explored the impact of fashion innovativeness, consumer innovativeness, fashion involvement, opinion leadership, and status, on consumer's purchase intention in Pakistan. Other studies have examined fashion adoption using factors such as personal values, the need for uniqueness, and social recognition, in order to predict purchase intention (Knight \& Kim, 2007).

Furthermore, there have been a selected number of studies on youth culture and fashion in Africa (DeBerrySpence, 2008; Gondola, 1999; Louchran, 2009; Thomas, 2003), however, with little focus on fashion adoption but rather exploring style identities through fashion. As a result, there seems to be a lack of literature on a South African youth culture and factors that influence their decisions to adopt fashion. More specifically, 
there seems to be very few studies that provide a comprehensive conceptual model exploring personality factors, as well as culture and gender issues and how these impact on fashion adoption. The significance of gaining insight into the youth and their buying behaviour will provide fashion marketers with a rich understanding of how to utilize their resources to accurately reach this profitable market segment. In view of this identified research gap, the present study provides a theoretical framework that explores the factors that influence fashion adoption among the youth in Johannesburg. The results would provide insights to marketing practitioners on how to target the youth in order to influence the rate at which they adopt new fashion trends. More specifically, factors such fashion consciousness; the need for uniqueness, interpersonal influence, individualism/collectivism and masculinity/femininity are explored. This study also contributes to existing literature in the field of fashion adoption and consumer behaviour, in the context of the South African youth. Additionally, issues such as culture and gender play a significant role and tend to have unique value to South Africa-based research. The purpose of this paper is therefore to investigate whether fashion consciousness, the need for uniqueness, interpersonal influence, individualism/collectivism and masculinity/femininity influence fashion adoption. The remainder of this paper provides background literature on the youth and fashion, the theoretical grounding of the study, and empirical literature on the research variables. This is followed by the conceptual model and hypotheses development, an overview of the research methodology, and the data analyses and presentation of the findings. Finally the results are discussed, implications provided and limitations and future research directions highlighted.

\section{Literature Review}

Youth culture and Fashion: The concept of youth culture spans several decades and across various disciplines (Bucholtz, 2002; Franzen, 2002). The development of youth culture is fueled by the growing sophistication of advertising and market segmentation strategies, and the dominant dimensions of youth ideology is identity, style and cultural innovation (Kjeldgaard \& Askegaard, 2006). On both an individual and cultural level, the youth constitute an in-progress identity, and 'being young' is associated with the rebellious breaking of style rules (Bucholtz, 2002). Despite their reputation of rebelliousness and the disruption to the social order, youth culture is a lucrative market segment (Chambers, 1985; Hebdige, 1979; Morin, 1962). The post World War Two era marked the beginning of two conflicting interests - between the youth as an antiestablishment culture on the one hand, and the commercial consumer culture on the other hand (Chambers, 1985). The model of the teenager has received significant interest as a cultural category in the post-World War Two economy of growth and affluence (Bennett, 1999). This viewpoint has led to the marketing industry becoming preoccupied with the youth, and during this time teenage identity became linked to leisure and hedonic consumption, with young, middle-class consumers being free from wage-earner responsibilities (Kjeldgaard \& Askegaard, 2006). As a result, the evidence of conspicuous consumption has marked the beginning of seeing the youth as a market with a diverse identity: a distinct market segment (Kjeldgaard \& Askegaard, 2006). The youth uses fashion as the most prominent means of identity expression (Balet, 2006; Kjeldgaard, 2009; Kjeldgaard \& Askegaard, 2006; Ziehe, 1992; Wilska, 2002). The theoretical legacy underlying the youth and their style emerged as a creative process through which subcultures differentiated themselves from mainstream marketplace orders (Goulding, Shanker \& Elliott, 2002; Ostberg, 2007). Rather than using style in a semiotic context, the youth use it as a means of identity expression, with emphasis on the relationship they have with style (Ziehe, 1992). The youth's choice of style is largely driven by the degrees of freedom they seek from the restrictions of society, and their desire to be authentic (Kjeldgaard, 2009). Fashion and dress has proved to be the ideal vehicle for South African youth to remap previously fixed racial identities (Corrigall, 2011).

Theoretical Grounding: The present paper is grounded in Sprole's (1979) Fashion Adoption Model and Craik's (1994) theory of factors influencing fashion adoption.

Sprole's (1979) Fashion Adoption Model: Sprole's (1979) Fashion Adoption Model is primarily used to measure style adoption, and factors influencing an individual's decision to adopt or reject a new style. The underlying conceptual foundation of this theory is that an individual's decision to adopt a new style is influenced by six traits, namely perfectionism, value consciousness, brand consciousness, fashion consciousness, shopping avoidance and support-seeking. 
The first trait, perfectionism, measures a consumer's desire for the best quality products. Those scoring high on this appear to be seekers of the very best whereas those who score low are less quality orientated. Individuals with high levels of perfectionism tend to be more careful with purchase decision and invest time and effort into comparison shopping. The second trait, value consciousness, refers to shoppers who search for products that are 'value for money'. They tend to be more prices sensitive and are regarded as the archetype of the economically conscious consumer. Thirdly, brand consciousness measures an individual's orientation towards buying the most expensive, well-known brand. Consumers scoring high on this are likely to believe that the higher the price of the product, the better its' quality. They tend to have some degree of fashion consciousness and prefer better department stores and specialty stores. The fourth trait, fashion consciousness, refers to novelty seeking individuals with high levels of fashion consciousness. They are up to date with the latest fashion trends and being in style is important to them. These consumers also tend to be fewer prices sensitive. Fifthly, shopping avoidance suggests that some consumers dislike shopping and tend to make rapid shopping trips. They do not view shopping as exciting or fun and are willing to make shopping sacrifices in order to save time. The last trait identified by Sprole's is that of support-seeking behaviour. These individuals tend to be confused about the marketplace and they often seek the advice and approval from friends when making a purchase decision. The present study incorporates two traits from Sprole's model, namely fashion consciousness and support seeking (susceptibility to interpersonal influence) into the proposed conceptual model.

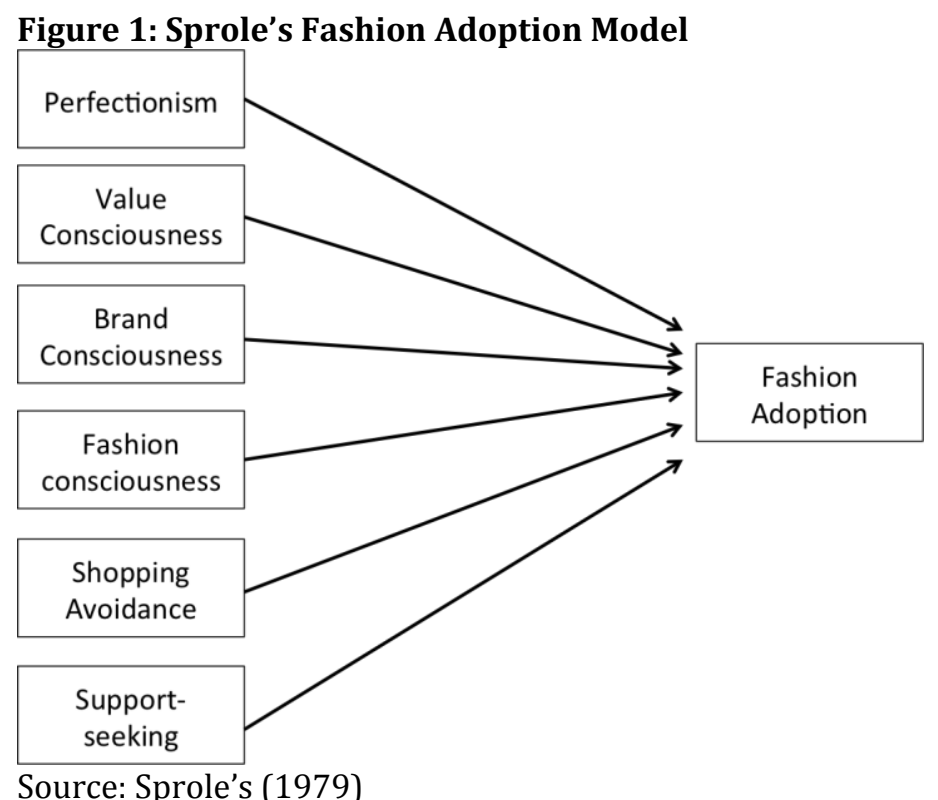

Source: Sprole's (1979)

Craik's (1994) Theory: Factors Influencing Fashion Adoption: The second theory underlying the present study is Craik's (1994) Theory of Factors influencing Fashion Adoption. This theory suggests that potential fashion instabilities influence an individual's decision to adopt a particular fashion: youth versus age, masculinity versus femininity, androgyny versus singularity, inclusiveness versus exclusiveness, and work versus play (Figure 2). 
Figure 2: Craik's Theory: Factors Influencing Fashion Adoption

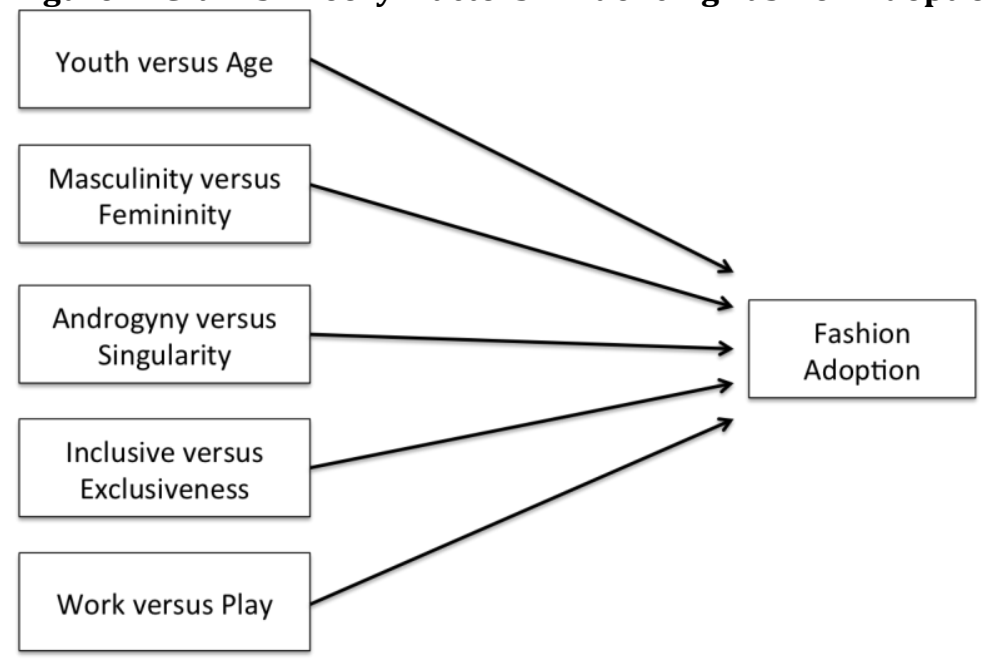

Source: Craik (1994)

According to Craik (1994), social change is believed to have a significant effect on fashion and reflects the specific time in history (Lehmann, 2000). The first factor, as described by Craik (1994), refers to the tension between youth versus age. This phenomenon is especially relevant in the twentieth century where separate fashion images are portrayed towards younger versus older consumers. Secondly, the role of gender and its' impact on fashion have received a widespread of attention over the last two centuries. Craik (1994) elaborated on the issue of gender by describing two categories, namely masculinity versus femininity, and androgyny versus singularity. In short, the tension between is regarded as typical male attire versus female attire, has undergone a radical shift over the last century, and more so over the last decade. Historically, the male ideal focused on strength, nobility and grace, whereas the female ideal focused on delicacy, femininity and shape (DeLong, 1998). However, the twentieth century witnessed the death of rigid male-centered values, and in both genders double identities have emerged, with woman being more assertive, and men more sensitive (Woodhill \& Sameuls, 2004). This concept is commonly referred to as androgyny, which is the act by an individual to engage in both masculine and feminine tasks (Woodhill \& Sameuls, 2004). As a result, while previous generations approached life with many unquestionable assumptions about gender, these prejudices are making way for blurred gender identities (Woodhill \& Sameuls, 2004). The fourth factor, as identified by Craik (1994), is the concept of inclusive versus exclusiveness. Craik (1994) is of the opinion that clothes are fundamental to the modern consumer's sense of identity and people tend to buy products that identify them with a particular group or to express their individualism. Simmel (1904) expresses this dual tendency to both conform and refrain from confirming as a paradox in which individual's desire belonging yet wants to portray personal identities. The last influencing factor is work versus play, which has been a persistent trend of the twentieth century by highlighting the difference in work clothing versus leisurewear. This trend emerged during the 1950's when families moved to the suburbs and engaged in outdoor activities and sports. As a result, distinct differences are evident between clothing that is regarded as acceptable work wear and casual wear.

Fashion Adoption: Fashion adoption predominantly refers to the adoption of a fashion over time, via a series of different stages (Goldsmith \& Reinecke, 1992). Within a broader framework, the classical model used to measure adoption, is Roger's (1985) innovation adoption model. Several adopter categories form part of the innovation adoption process, such as the innovators, the early adopters, the early majority, the late majority, and the laggards (Rogers, 2005).

Fashion Consciousness: Fashion consciousness is an important dimension that influences the decisionmaking of product adoption, especially with regards to fashion clothing (Belleau, Nowlin, Summers \& Jiao Xu, 2001; Khare \& Rakesh, 2010; King \& Ring, 1980; Sproles \& Kendall, 1986; Wells \& Tigert, 1971). It is defined as an individual's involvement with styles or fashion (Nam, Hamlin, Gam, Kang, Kim, Kumphai, 2007; Sproles \& Kendall, 1986; Wells \& Tigert, 1971). Consumers with high levels of fashion consciousness are likely to be 
younger and better educated, than non-fashion conscious individuals (Crask \& Reynolds, 1978). These early adopters of new fashion styles - who are also referred to as fashion change agents - are more interested in and knowledgeable about fashion products (King \& Ring, 1980). They have innovative style profiles, and although they are not completely up-to-date with all current styles, they are able to elicit interest among groups for future adoption (King \& Ring, 1980). These fashion agents often establish group standards of dress behaviour, due to their ability to influence and stimulate fashion adoption (King \& Ring, 1980).

Need for Uniqueness: One's desire for uniqueness is a motivational factor, and is theorized as a motivational drive that compels individuals to be different from others (Tian Bearden \& Hunter, 2001). The desire for social distinction usually arises when an individual feels a threat to their identity, that occurs when they perceive to be similar to others, and thus they seek a sense of uniqueness (Tian et al., 2001). For example, the purchase of vintage goods or personalized items that are not typically available is often a way for consumers to display their resistance to conformity (Tian et al., 2001). Thus, consumers possessing a high requirement for uniqueness will seek to avoid popular product preferences, and therefore will familiarize themselves with unique offerings (Tian et al., 2001). The desire for social distinction influences new product adoption and variety-seeking behaviour, and this is reflected in one's choice of products (McAlister \& Pessemier, 1982).

Susceptibility to Interpersonal Influence: Susceptibility to interpersonal influence is defined as an individual's need to identify with the opinions of others through the acquisition of products (Bearden et al., 1989). Such individuals often portray the tendency to learn about products by seeking information from others, and the willingness to conform to the expectations of others regarding purchase decisions (Bearden et al., 1989). Susceptibility to interpersonal influence is classified into two categories, namely normative influence and informational influence (Deutsch \& Gerard, 1955). Normative influence is the tendency to conform to others' expectations, and informational influence refers to one's reliance on information obtained from others (Deutsch \& Gerard, 1955). Normative influence further describes the adoption of and compliance with, others behaviour to satisfy a self-defining relationship with a group or individual (Clark \& Goldsmith, 2006).

Individualism/Collectivism: The concept of individualism/collectivism is a dimension of Hofstede's (1983) cultural framework and refers to the strength of the ties between individuals in a community. Within individualistic communities, members tend to primarily focus on their own individuals needs and emotional independence, whereas collectivist communities value group decision-making and reflect emotional dependence on others (Hofstede, 1983). In the context of fashion, consumers in individualistic societies show stronger preference for clothing that expresses their unique self and they are more likely to indulge in selfgratification. On the other hand, individuals in collectivist cultures regard social approval or 'fitting in' is a key determinant when making purchasing decisions and therefore tend to buy clothing that is socially acceptable (Millan, De Pelsmacker \& Wright, 2011). Therefore, in individualistic cultures, brand strategies that emphasize variety and novelty positively affect market share, whereas in collectivist cultures, brand strategies that reinforce group membership and affiliation enhance brand performance (Roth, 1995).

Masculinity/Femininity: Historically, the practice of consumption and more specifically fashion consumption has mainly been associated with being a woman's role. For example, in masculine dominated societies, where the emphasis is on wealth, success, achievement etc., individuals are more likely to be innovators and the first to adopt new products (Singh, 2006). Consequently, in cultures where feminine traits dominate, individuals are being more likely to conform to social norms, and therefore be fashion followers rather than fashion leaders (Singh, 2006). However, the way in which men views themselves as shoppers have changed and more androgynous styles has emerged in recent years (Bakewell, Mitchell \& Rothwell, 2006). This gave way to the shifting nature of male identities in the $21^{\text {st }}$ century as fashionable men found new ways to express their masculinity through fashion consumption (Bowstead, 2015).

Proposed Conceptual Model and Hypotheses Development: By means of a comprehensive conceptual model, the present study aims to fill the gap in literature on factors influencing fashion adoption among the youth in Johannesburg. The model proposes that fashion consciousness (Fash), the need for uniqueness (Need), susceptibility to interpersonal influence (Susc), collectivism/individualism (Coll) and masculinity/femininity (Masc) influence fashion adoption (Adop). 
Figure 3: The proposed conceptual model

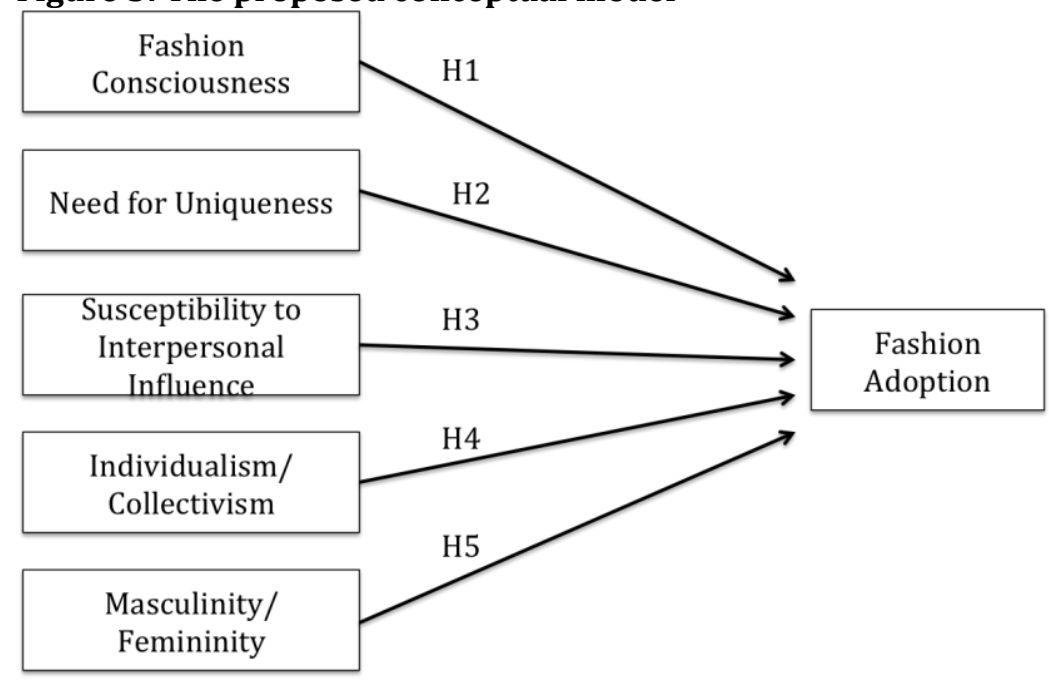

Source: Compiled by researcher (2015)

\section{Hypotheses Development}

The following section presents the hypotheses development for the present study.

Fashion Consciousness and Fashion Adoption (H1): Fashion consciousness and its influence on style adoption have been explored in several studies: for example, in a study conducted by Lertwannawit and Mandhachitara (2012), the findings indicate a strong relationship between fashion consciousness and status consumption. Furthermore, Goldsmith et al. (2015) found that fashion consciousness plays an important role in innovative purchasing behaviour among consumers when shopping for clothing products. Therefore, deducing from the literature and the empirical evidence mentioned above, the present study hypothesises that:

H1: Fashion consciousness positively influences fashion adoption

Need for Uniqueness and Fashion Adoption (H2): Cervellon, Carey \& Harms, (2012) found that one's need for uniqueness is a dominant driver in shopping for vintage clothing. Similarly, in a study conducted by Tian et al. (2001), the results indicated that the purchase of vintage goods or personalized items is often a way for consumers to display their resistance to conformity. Thus, consumers possessing a high requirement for uniqueness will seek to avoid popular product preferences, and therefore will familiarize themselves with unique offerings (Tian et al., 2001). The desire for social distinction influences new product adoption and variety-seeking behaviour, and this is reflected in one's choice of products (McAlister \& Pessemier, 1982). Therefore, inferring from the literature and the empirical evidence mentioned above, the present study hypothesises that:

H2: Need for uniqueness positively influences fashion adoption

Susceptibility to Interpersonal Influence and Fashion Adoption (H3): Another factor that influences fashion adoption is one's susceptibility to interpersonal influence (Belleau et al., 2001; Lertwannawit \& Mandhachitara, 2012). For example, Khare \& Rakesh, (2012) found that Indian woman's fashion involvement is influenced by normative values, especially among younger age groups. Furthermore, although having an indirect effect, susceptibility to interpersonal influence has an effect on status consumption among fashion conscious consumers (Lertwannawit \& Mandhachitara, 2012). Upon examining the relationship between interpersonal influence and ecologically conscious buying behaviour, the findings reveal that normative influence is a predictor of green buying behaviour. Therefore, social conformity is one of the significant predictors of purchasing fashion goods (Park, Rabolt \& Sook Jeon, 2006). Therefore, inferring from the literature and the empirical evidence mentioned above, the present study hypothesises that:

H3: Susceptibility to interpersonal influence positively influences fashion adoption 
Individualism/Collectivism and Fashion Adoption (H4): Culture has a powerful force on consumer adoption (Arnould et al., 2005; Markus \& Kitayama, 1991). In a global marketplace, individuals might acquire a fluid sense of identity between traditional cultural values and personal identities, as shaped by the conditions of modernity (Steenkamp, 2001). For example, in a study conducted by Al-Mutawa (2013), the results indicated that Muslim female consumers rework western fashion trends to suit their cultural beliefs and personal style. They therefore recreate the meaning of global luxury fashion to generate 'modestly sexy' representations of themselves (Al-Mutawa, 2013). Saad, Cleveland and Ho (2015) suggested that individualists are more likely to express higher levels of confidence as compared to collectivists. Furthermore, Goldsmith, Moore and Beaudoin (1999) profiled fashion innovators and found that using selfimage to appeal to consumers was of paramount importance in fashion marketing. Therefore, inferring from the literature and the empirical evidence mentioned above, this study hypothesises that:

H4: Individualism/Collectivism positively influences fashion adoption

Masculinity/Femininity and Fashion Adoption (H5): Shephard, Kinley and Josiam (2014) found that males and females exhibit different behaviour with respect to the adoption stage of fashion related items. Through further empirical investigation, Shephard et al. (2014) established that female college students showed significant evidence of pleasure in shopping for fashion brands as compared to their male counterparts. Over the years there has been significant changes in the manner in which men view themselves as shoppers and the rise of men's fashion magazines has led to the redefining masculinity (Bakewell, Mitchell \& Rothwell, 2006). Bakewell et al. (2006) further stated that masculinity was redefined by using men as fashion icons to promote appearance concerns and associate clothing and style with success thereby encouraging men to view their social value as being determined by what they look like. Therefore, deducing from the literature and the empirical evidence mentioned above, this study hypothesises that:

H5: Masculinity/Femininity positively influences fashion adoption

\section{Methodology}

The following section provides an overview of the respondent sample profile and data collection, the instrument design and questionnaire, followed by a presentation of the results. The study findings are then presented against the proposed hypotheses and the analysis was conducted using SPSS 22 and AMOS 22 statistical software.

Sample and Data Collection: The population of interest for the study was students in Johannesburg. By means of a quantitative study, 400 self-administered surveys were distributed amongst a sample of students from the University of the Witwatersrand. The students were all between the ages of 18 and 30. The sample of respondents was selected by means of simple random sampling.

Measurement Instrument and Questionnaire Design: Research scales were operationalized on the basis of previous work. Adequate modifications were made in order to fit the current research context and purpose. The first variable, fashion consciousness, was measured using a 7-item Likert scale that was adapted from Bruner and Hensel's (1998) 7-item fashion consciousness scale. The need for uniqueness was measured using a 7-point Likert scale adapted from Tian, Bearden and Hunter's (2001) 9-item need for uniqueness scale. Further, 7-point Likert scale was used to measure interpersonal influence. This scale was modified from the original 'susceptibility to interpersonal influence' scale by Bearden, Netemeyer and Teel (1989). Individualism/ collectivism were measured using a combination of Triandis (1991) INDCOL scale and Hui's individualism/collectivism scale. This comprised of a 7-point Likert scale. Finally, for masculinity and femininity, dimensions were derived from the BEM Sex-role Inventory (BSRI) and adopted to suit the context of the present study. The latter scale comprised of a 7-item Likert scale.

\section{Results of the Study}

Respondent Profile: The profile of the participants is presented in Table 1 below. Thereafter a discussion of the sample's demographic profile follows. 
Table 1: Sample Demographic Profile

\begin{tabular}{llllll}
\hline Gender & Frequency & Percentage & Race & Frequency & Percentage \\
\hline Male & 132 & $33 \%$ & Black & 105 & $27 \%$ \\
Female & 268 & $67 \%$ & White & 204 & $52 \%$ \\
Total & 400 & $100 \%$ & Asian & 7 & $2 \%$ \\
Age & Frequency & Percentage & Coloured & 17 & $4 \%$ \\
$18-19$ & 88 & $22 \%$ & Indian & 51 & $13 \%$ \\
$20-25$ & 301 & $75 \%$ & Other & 7 & $2 \%$ \\
$26+$ & 11 & $3 \%$ & Total & 391 & $100 \%$ \\
Total & 400 & $100 \%$ & & & \\
\hline
\end{tabular}

The sample comprised $67 \%$ females and 33\% males, while $75 \%$ were between 20 and 25 years of age, $22 \%$ between the ages of 18 and 19, and 3\% were older than 26 years. Whites accounted for more than half of the total sample of participants (52\%), while 27\% accounted for blacks. The remainder of the sample consisted of Indians (13\%), Coloureds (4\%) and Asians (2\%).The following section provides an overview of the scale reliability (Table 2).

Scale Reliability: All the measurement scales were tested for reliability by means of analysing the Cronbach Alpha Coeeficient. Table 2 presents the findings.

Table 2: Reliability Test

\begin{tabular}{lllllll}
\hline Variable & Fash & Coll & Adop & Susc & Masc & Need \\
\hline Cronbach's & 0.86 & 0.66 & 0.88 & 0.92 & 0.77 & 0.96 \\
Alpha & & & & & &
\end{tabular}

Alpha

Note: Fash, fashion; Adop, adoption; Susc, susceptibility to interpersonal influence; Coll, collectivism; Masc, masculinity; Need, need for uniqueness.

As evident from the results in Table 2, the majority of the Cronbach's alpha coefficients were above 0.70 , with the exception of individualism/collectivism $(\alpha=0.66)$ whilst the composite reliability indexes ranged from 0.66 to 0.96 . Therefore confirming the scales met the recommended threshold of 0.7 as recommended by (Nunnally \& Bernstein, 1994).

Regression Results: This section discusses the descriptive statistics, the linear regression model equation, correlations between the dependent and independent variables and lastly the standardised coefficients for each of the proposed hypotheses.

Fashion Consciousness and Fashion Adoption: For the first hypothesis, fashion consciousness and fashion adoption, the descriptive statistics are presented in Table 3, followed by a discussion thereof.

Table 3: Descriptive Statistics: Fashion consciousness and adoption

\begin{tabular}{llll}
\hline & Mean & Std. Deviation & $\mathbf{N}$ \\
\hline Adop & 4,2975 & 1,50281 & 400 \\
Fash & 4,6460 & 1,31454 & 400 \\
\hline
\end{tabular}

As indicated in Table 3(above) the mean values for adoption and fashion consciousness are 4.29 and 4.64 respectively while the standard deviation values are 1.50 and 1.31 for these variables respectively. Since the standard deviation values were between the thresholds of $(-2$ and +2$)$ it means that the sample was fairly distributed and members of this particular group did not vary much from the mean value for the group. In other words, this implies that the data is skewed therefore low chances of respondents providing extremely biased views with regards to the relationship between fashion consciousness and fashion adoption.

Upon testing the linear regression model, the following equation was used:

$\mathbf{y}=\boldsymbol{\beta}_{0}+\boldsymbol{\beta}_{1} X+\varepsilon$

$\mathrm{y}=$ Dependent Variable: Adoption

$\mathrm{x}=$ Independent Variable: Fashion 
Table 4: Fashion consciousness and adoption correlation

\begin{tabular}{|c|c|c|c|c|c|c|c|c|c|c|}
\hline \multicolumn{5}{|c|}{ Correlations } & \multicolumn{6}{|l|}{ ANOVA $^{a}$} \\
\hline & & Adop & Fash & & Model & $\begin{array}{l}\text { Sum of } \\
\text { Squares }\end{array}$ & df & $\begin{array}{l}\text { Mean } \\
\text { Square }\end{array}$ & $\mathbf{F}$ & Sig. \\
\hline \multirow{2}{*}{$\begin{array}{l}\text { Pearson } \\
\text { Correlation }\end{array}$} & Adop & 1,000 & 0,270 & 1 & Regression & 65,905 & 1 & 65,905 & 31,405 & $0.000^{b}$ \\
\hline & Fash & 0,270 & 1,000 & & Residual & 835,213 & 398 & 2,099 & & \\
\hline \multirow{2}{*}{$\begin{array}{l}\text { Sig. } \\
\text { tailed) }\end{array}$} & Adop & & 0,000 & & Total & 901,118 & 399 & & & \\
\hline & Fash & 0,000 & & & & & & & & \\
\hline \multirow[t]{2}{*}{$\mathrm{N}$} & Adop & 400 & 400 & & & & & & & \\
\hline & Fash & 400 & 400 & & & & & & & \\
\hline
\end{tabular}

Note: a. Dependent Variable: Adop; b. Predictor: Fash

As indicated in Table 4, the correlation between the predictor variable (fashion consciousness) and the dependent variable (adoption) is 0.270 which is below the threshold of 1 , therefore showing that a correlation between the two variables exists. Hypothesis 1 is therefore supported. The positive value also denotes evidence of a positive linear correlation; however the linear correlation is distant from 1 implying that the relationship between fashion consciousness and adoption is relatively weak. In the following section the coefficient for fashion consciousness is presented Table 5.

Table 5: Fashion consciousness coefficient

\begin{tabular}{|c|c|c|c|c|c|c|c|}
\hline \multicolumn{8}{|l|}{ Coefficients $^{\mathbf{a}}$} \\
\hline & \multicolumn{2}{|c|}{$\begin{array}{l}\text { Unstandardized } \\
\text { Coefficients }\end{array}$} & \multicolumn{2}{|c|}{$\begin{array}{l}\text { Standardized } \\
\text { Coefficients }\end{array}$} & \multirow[b]{2}{*}{ Sig. } & \multicolumn{2}{|c|}{$\begin{array}{l}95,0 \% \text { Confidence } \\
\text { Interval for B }\end{array}$} \\
\hline Model & B & $\begin{array}{l}\text { Std. } \\
\text { Error }\end{array}$ & Beta & $\mathbf{t}$ & & $\begin{array}{l}\text { Lower } \\
\text { Bound }\end{array}$ & $\begin{array}{l}\text { Upper } \\
\text { Bound }\end{array}$ \\
\hline 1 (Constant) & 2,861 & 0,266 & & 10,742 & 0,000 & 2,337 & 3,385 \\
\hline Fash & 0,309 & 0,055 & 0,270 & 5,604 & 0,000 & 0,201 & 0,418 \\
\hline \multicolumn{8}{|c|}{ a. Dependent Variable: Adop } \\
\hline
\end{tabular}

The Beta value for fashion consciousness and adoption is $0.270(\beta=0.270)$ and the p value is significant $(p<$ $0.005)$. This relationship posits that the more fashion conscious an individual is, the more likely that they will adopt a new fashion style.

Need for Uniqueness and Fashion Adoption: For the second hypothesis, the need for uniqueness and fashion adoption, the descriptive statistics are presented in Table 6, followed by a discussion thereof.

Table 6: Descriptive statistics: Need for uniqueness and adoption

\begin{tabular}{cccc}
\hline & Mean & Std. Deviation & N \\
\hline Adop & 4,2975 & 1,50281 & 400 \\
Need & 4,4857 & 1,55113 & 400 \\
\hline \multicolumn{3}{l}{ Note: Adop= Adoption; Need= Need for uniqueness }
\end{tabular}

As indicated in Table 6, the mean values for adoption and need for uniqueness are 4.29 and 4.64 respectively. While the standard deviation values are 1.50 and 1.55 for adoption and fashion consciousness respectively. This implies that that the sample was evenly distributed and the respondents provided views that were not too different from the mean responses of the group in terms of their views regarding the influence of the need for uniqueness on fashion adoption.

Upon testing the linear regression model, the following equation was used:

$y=\beta_{0}+\beta_{1} X+\varepsilon$ 
$\mathrm{y}=$ Dependent Variable: Adoption

$\mathrm{x}=$ Independent Variable: Fashion

Table 7: Need for uniqueness and adoption correlation

\begin{tabular}{|c|c|c|c|c|c|c|c|c|c|c|}
\hline Correlatio & & Adop & Need & & $\begin{array}{l}\text { ANOVA } \\
\text { Model }\end{array}$ & $\begin{array}{l}\text { Sum of } \\
\text { Squares }\end{array}$ & & $\begin{array}{l}\text { Mean } \\
\text { Square }\end{array}$ & F & Sig. \\
\hline \multirow{2}{*}{$\begin{array}{l}\text { Pearson } \\
\text { Correlatio } \\
\mathrm{n}\end{array}$} & Adop & 1,000 & 0,356 & 1 & $\begin{array}{l}\text { Regressio } \\
n\end{array}$ & 114,505 & 1 & 114,505 & $\begin{array}{l}57,93 \\
6\end{array}$ & $0.000^{\mathrm{b}}$ \\
\hline & Need & 0,356 & 1,000 & & Residual & 786,612 & 398 & 1,976 & & \\
\hline \multirow{2}{*}{$\begin{array}{l}\text { Sig. } \\
\text { tailed })\end{array}$} & Adop & & 0,000 & & Total & 901,118 & 399 & & & \\
\hline & Need & ,000 & & & \multirow{3}{*}{\multicolumn{3}{|c|}{$\begin{array}{l}\text { a. Dependent Variable: Adop } \\
\text { b. Predictors: (Constant), } \\
\text { Need }\end{array}$}} & & & \\
\hline \multirow[t]{2}{*}{$\mathrm{N}$} & Adop & 400 & 400 & & & & & & & \\
\hline & Need & 400 & 400 & & & & & & & \\
\hline
\end{tabular}

Note: a. Dependent Variable: Adop; b. Predictor: Need

As indicated in Table 7, the correlation between the predictor variable (Need for uniqueness) and the dependent variable (Adoption) is 0.356 which is below the threshold of 1 , therefore showing that a correlation between the two variables exists. Hypothesis 2 is therefore supported. The positive value also denotes evidence of a positive linear correlation however the linear correlation is distant from 1 implying that the relationship between fashion consciousness and adoption is relatively weak. In other words, the higher the need for uniqueness, the more likely that an individual will adopt a new fashion style. In the section that follows the need for uniqueness coefficient is presented (Table 8).

Table 8: Need for uniqueness coefficient

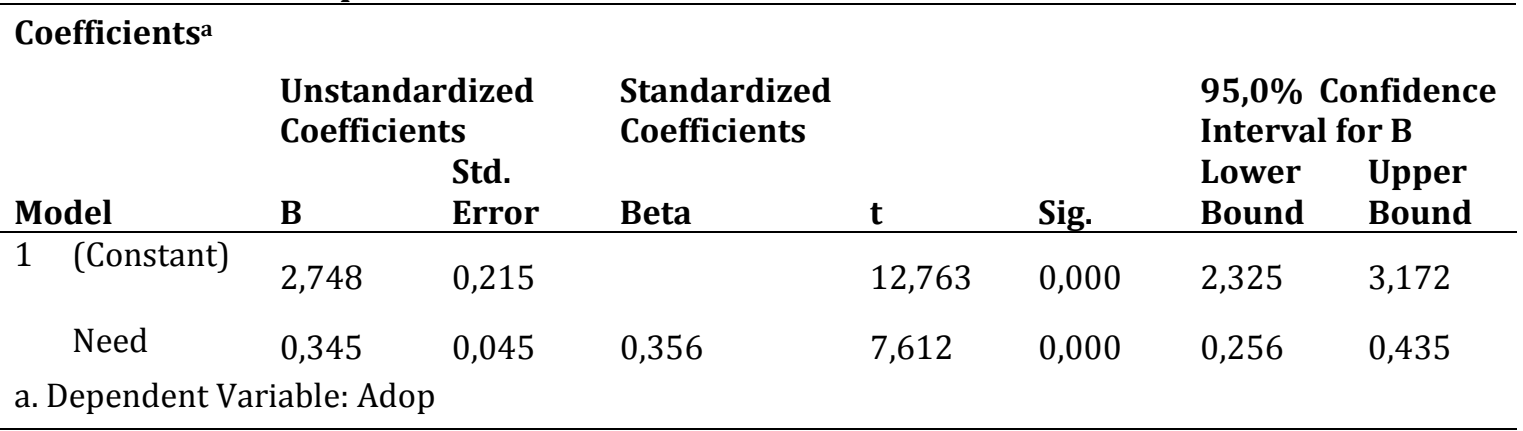

The results in Table 8 reflects a Beta value of $0.356(\beta=0.356)$ for the need for uniqueness and the p value is significant $(\mathrm{p}<0.005)$.This suggests that the more consumers seek to be unique the more the more likely there are to adopt a new fashion style.

Susceptibility to Interpersonal Influence and Fashion Adoption: The descriptive statistics results for the third hypothesis, susceptibility to interpersonal influence and fashion adoption, are presented in Table 9, followed by a discussion thereof.

Table 9: Descriptive Statistics: Susceptibility to interpersonal influence and adoption

\begin{tabular}{llll}
\hline & Mean & Std. Deviation & N \\
\hline Adop & 4,2975 & 1,50281 & 400 \\
Susc & 2,8647 & 1,32917 & 400 \\
\hline
\end{tabular}

Adop= Adoption; Susc=Susceptibility to interpersonal influence 
As indicated in Table 9(above), the mean values for adoption and susceptibility to interpersonal influence are 4.30 and 2.86 respectively while the standard deviation values are 1.50 and 1.33 falling between the recommended thresholds of $(-2$ and +2$)$ implying that with regards to how susceptibility of interpersonal influence affects the extent of fashion adoption the respondents provided views that did not veer too much from the mean responses of the group.

Upon testing the linear regression model, the following equation was used:

$\mathbf{y}=\boldsymbol{\beta}_{0}+\boldsymbol{\beta}_{1} \mathrm{X}+\boldsymbol{\varepsilon}$

$\mathrm{y}=$ Dependent Variable: Adoption

$\mathrm{x}=$ Independent Variable: Fashion

Table 10: Susceptibility to interpersonal influence and adoption correlation

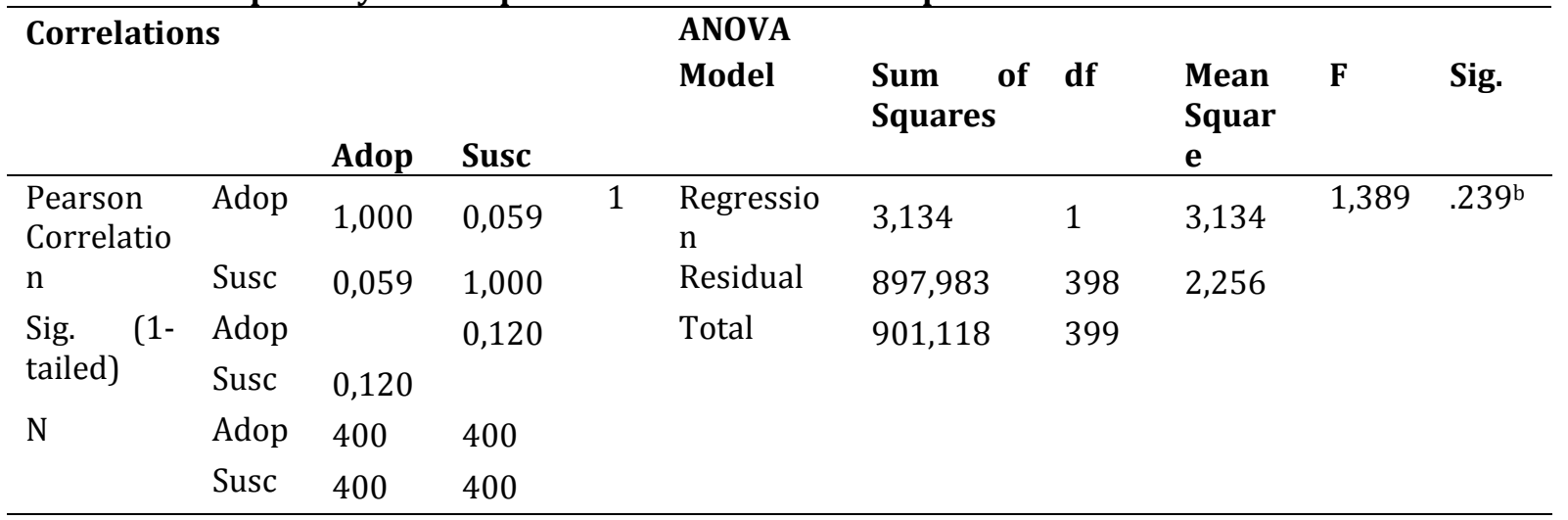

Note: a. Dependent Variable: Adoption (Adop); b. Predictor: Susceptibility to interpersonal influence (Susc)

In table 10 (above), it can be observed that the correlation between the predictor variable (susceptibility to interpersonal influence) and the dependent variable (adoption) is 0.059 which is below the threshold of 1 . This indicates that a correlation between the two variables exists, however it is very weak as it is distant from 1. Hypothesis three is therefore not supported. Table 11presents the coefficient for susceptibility to interpersonal influence and adoption.

Table 11: Susceptibility to interpersonal influence

\begin{tabular}{|c|c|c|c|c|c|c|c|}
\hline \multicolumn{8}{|l|}{ Coefficients $^{a}$} \\
\hline & \multicolumn{2}{|c|}{$\begin{array}{l}\text { Unstandardized } \\
\text { Coefficients }\end{array}$} & \multicolumn{2}{|c|}{$\begin{array}{l}\text { Standardized } \\
\text { Coefficients }\end{array}$} & \multirow[b]{2}{*}{ Sig. } & \multicolumn{2}{|c|}{$\begin{array}{l}95,0 \% \text { Confidence } \\
\text { Interval for B }\end{array}$} \\
\hline Model & B & $\begin{array}{l}\text { Std. } \\
\text { Error }\end{array}$ & Beta & $t$ & & $\begin{array}{l}\text { Lower } \\
\text { Bound }\end{array}$ & $\begin{array}{l}\text { Upper } \\
\text { Bound }\end{array}$ \\
\hline 1 (Constant) & 4,106 & 0,179 & & 22,989 & 0,000 & 3,755 & 4,458 \\
\hline Susc & 0,067 & 0,057 & 0,059 & 1,179 & 0,239 & $-0,045$ & 0,178 \\
\hline a. Dependent V & iable: A & & & & & & \\
\hline
\end{tabular}

In Table 11(above) it can be observed that the Beta value for susceptibility to interpersonal influence is 0.059 $(\beta=0.059)$ and the $p$-value is insignificant $(p>0.05)$. This implies that susceptibility to interpersonal does not influence individuals' decision to adopt a new fashion style.

Individualism/Collectivism and Fashion Adoption: For the fourth hypothesis, individualism/collectivism and fashion adoption, the descriptive statistics are presented in Table 12, followed by a discussion. 
Table 12: Descriptive Statistics

\begin{tabular}{llll}
\hline & Mean & Std. Deviation & N \\
\hline Adop & 4,2957 & 1,50428 & 400 \\
Coll & 4,6689 & 1,05481 & 400 \\
\hline
\end{tabular}

As indicated in Table 12(above) the mean values for adoption and collectivism are 4.30 and 4.67 respectively while the standard deviation values are 1.50 and 1.05 falling between the thresholds of $(-2$ and +2$)$.This implies that the sample is evenly distributed and that there is low variation amongst the views of the respondents and those of the group concerning the influence of individualism/collectivism on fashion adoption.

Upon testing the linear regression model, the following equation was used:

$\mathbf{y}=\boldsymbol{\beta}_{0}+\boldsymbol{\beta}_{1} \mathbf{X}+\varepsilon$

$\mathrm{y}=$ Dependent Variable: Adoption

$\mathrm{x}=$ Independent Variable: Fashion

Table 13: Collectivism and adoption correlation

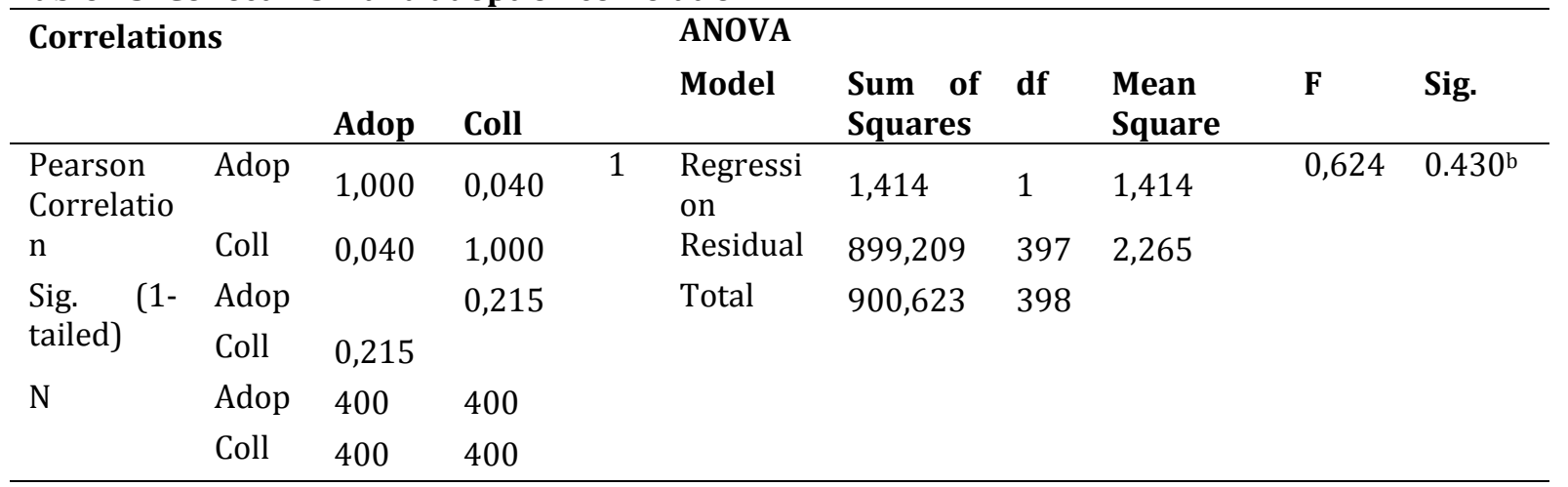

Note: a. Dependent Variable: Adoption (Adop); b. Predictor: Collectivism (Coll)

In table 13(above) it can be observed that the correlation between the predictor variable (collectivism) and the dependent variable (Adoption) is 0.040 which is lower the threshold of 1 , thereby revealing that there is a correlation between the two variables. The positive value also reveals evidence of a positive linear correlation however the linear correlation is distant from 1 positing that the relationship between collectivism and adoption is very weak. This suggests that collectivism does not have an impact on consumer's adoption of fashion brands. Hypothesis four is therefore not supported. Table 14 in the following section presents the individualism/collectivism coefficient.

Table 14: Collectivism coefficient

\begin{tabular}{|c|c|c|c|c|c|c|c|}
\hline \multirow[b]{2}{*}{ Model } & \multicolumn{2}{|c|}{$\begin{array}{l}\text { Unstandardized } \\
\text { Coefficients }\end{array}$} & \multicolumn{2}{|c|}{$\begin{array}{l}\text { Standardized } \\
\text { Coefficients }\end{array}$} & \multirow[b]{2}{*}{ Sig. } & \multicolumn{2}{|c|}{$\begin{array}{l}95,0 \% \text { Confidence } \\
\text { Interval for B }\end{array}$} \\
\hline & B & $\begin{array}{l}\text { Std. } \\
\text { Error }\end{array}$ & Beta & $\mathbf{t}$ & & $\begin{array}{l}\text { Lower } \\
\text { Bound }\end{array}$ & $\begin{array}{l}\text { Upper } \\
\text { Bound }\end{array}$ \\
\hline 1 (Constant) & 4,032 & 0,342 & & 11,779 & 0,000 & 3,359 & 4,705 \\
\hline Coll & 0,057 & 0,072 & 0,040 & 0,790 & 0,430 & $-0,084$ & 0,197 \\
\hline a. Dependent V & iable: A & & & & & & \\
\hline
\end{tabular}

It is evident from Table 14 (above) that the Beta value for the collectivism is $0.040(\beta=0.040$ ) and the $p$ value is insignificant at the level of significance is $(\mathrm{p}<0.005)$ suggesting that individualism/collectivism does not influence consumer's decision to adopt a new fashion style. 
Masculinity/Femininity and Fashion Adoption: The descriptive statistics results for the last hypothesis, masculinity/femininity and fashion adoption are presented in Table 15, followed by a discussion thereof.

Table 15: Descriptive: Masculinity and adoption

\begin{tabular}{llll}
\hline & Mean & Std. Deviation & N \\
\hline Adop & 4,2975 & 1,50281 & 400 \\
Masc & 3,7619 & 0,61494 & 400 \\
\hline
\end{tabular}

As indicated in Table 15 on the previous page, the mean values for adoption and masculinity are 4.30 and 3.76 respectively while the standard deviation is 1.50 and 0.61 thereby falling below the threshold of (-2and +2 ). This implies that the sample was evenly distributed and demonstrates low variation between the views of the respondents and those of the group regarding masculinity/femininity's influence on fashion adoption.

Upon testing the linear regression model, the following equation was used:

$\mathbf{y}=\boldsymbol{\beta}_{0}+\boldsymbol{\beta}_{1} X+\varepsilon$

$\mathrm{y}=$ Dependent Variable: Adoption

$\mathrm{x}=$ Independent Variable: Fashion

Table 16: Masculinity and adoption correlation

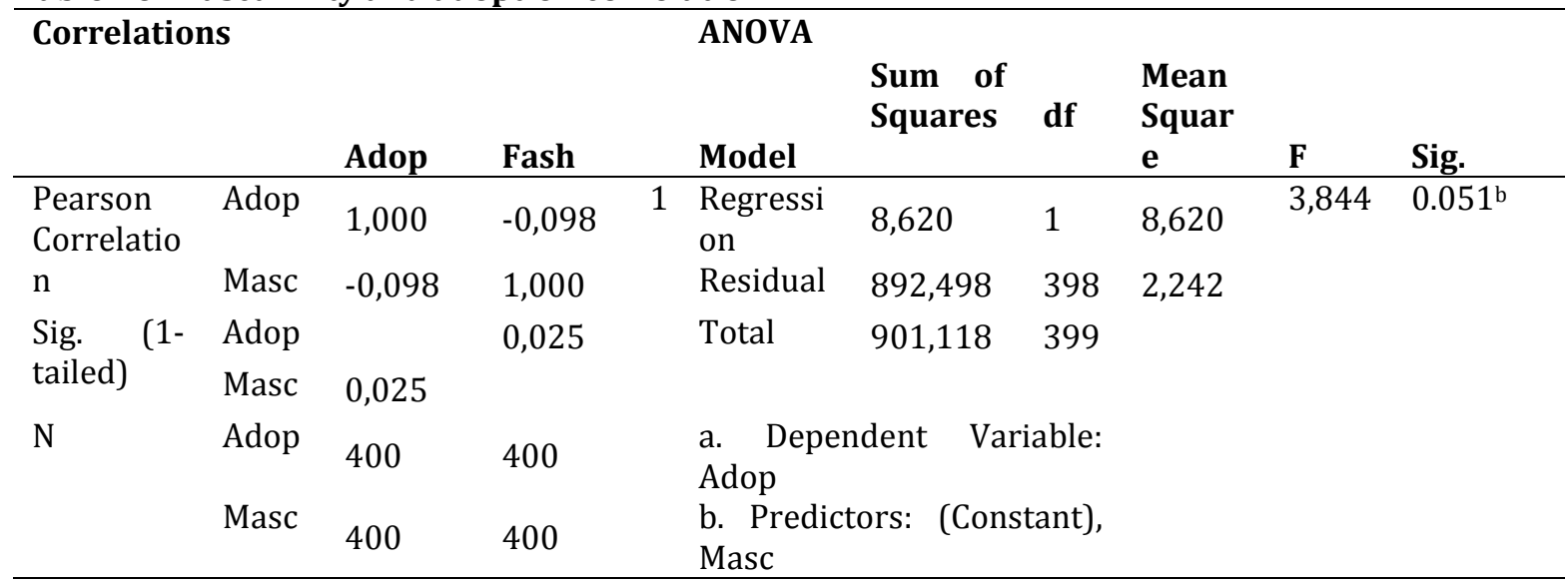

Note: a. Dependent Variable: Adoption (Adop); b. Predictor: masculinity (masc)

In table 16(above), it is evident that the correlation between the predictor variable (masculinity/femininity) and the dependent variable (adoption) is $-0,098$. This value is lower the threshold of 1 thereby revealing that there is a correlation between the two variables, however an inverse relationship exists. In other words, the more masculine individuals are, the less likely that they will adopt a new fashion style. Therefore, feminine consumers are more likely to adopt a new fashion style. The following section presents the masculinity/femininity coefficient (Table 17).

Table 17: Masculinity coefficient

\begin{tabular}{|c|c|c|c|c|c|c|c|}
\hline \multirow[b]{2}{*}{ Model } & \multicolumn{2}{|c|}{$\begin{array}{l}\text { Unstandardized } \\
\text { Coefficients }\end{array}$} & \multicolumn{2}{|c|}{$\begin{array}{l}\text { Standardized } \\
\text { Coefficients }\end{array}$} & \multirow[b]{2}{*}{ Sig. } & \multicolumn{2}{|c|}{$\begin{array}{l}95,0 \% \text { Confidence } \\
\text { Interval for B }\end{array}$} \\
\hline & B & $\begin{array}{l}\text { Std. } \\
\text { Error }\end{array}$ & Beta & $\mathbf{t}$ & & $\begin{array}{l}\text { Lower } \\
\text { Bound }\end{array}$ & $\begin{array}{l}\text { Upper } \\
\text { Bound } \\
\end{array}$ \\
\hline 1 (Constant) & 5,197 & 0,465 & & 11,183 & 0,000 & 4,283 & 6,110 \\
\hline Masc & $-0,239$ & 0,122 & $-0,098$ & $-1,961$ & 0,051 & $-0,479$ & 0,001 \\
\hline a. Dependent Var & ible: Ado & & & & & & \\
\hline
\end{tabular}


As presented in Table 17, the Beta value for masculinity/femininity is $-0,098(\beta=-0.098)$ and the $p$ value is significant $(p<0.010)$. This suggests that the more the masculine a consumer is the less likely that they would adopt a fashion brand.

Summary of Results: Table 18 presents a comparison of coefficients observed in the present study. The findings reveal that three of the five hypotheses are supported, namely fashion consciousness, the need for uniqueness and masculinity/femininity. Therefore indicating that the latter variables have an influence on fashion adoption. The strongest relationship was found to be between the need for uniqueness and fashion adoption, followed by fashion consciousness and fashion adoption. An inverse relationship was found between masculinity/femininity and fashion adoption. On the other hand, susceptibility to interpersonal influence and individualism/collectivism do not influence fashion adoption.

Table 18: Comparison of Coefficients

\begin{tabular}{|c|c|c|c|c|}
\hline Relationship & $\begin{array}{l}\text { Standardized } \\
\text { Coefficients } \\
\text { Beta }\end{array}$ & $\begin{array}{l}\text { Pearson } \\
\text { Correlation }\end{array}$ & P-Value & Outcome \\
\hline Fash\&Adop & 0,270 & 0,270 & 0,000 & $\begin{array}{l}\text { Supported and significant at } \\
(p<0.01)\end{array}$ \\
\hline Need\&Adop & 0,356 & 0,356 & 0,000 & $\begin{array}{l}\text { Supported and significant at } \\
(p<0.01)\end{array}$ \\
\hline Susc\& Adop & 0,059 & 0,059 & 0,239 & $\begin{array}{l}\text { Unsupported and } \\
\text { insignificant at }(\mathrm{p}<0.01)\end{array}$ \\
\hline Coll\&Adop & 0,040 & 0,040 & 0,430 & $\begin{array}{l}\text { Unsupported and } \\
\text { insignificant at }(\mathrm{p}<0.01)\end{array}$ \\
\hline Masc\& Adop & $-0,098$ & $-0,098$ & 0,051 & $\begin{array}{l}\text { Supported and significant at } \\
(\mathrm{p}<0.10)\end{array}$ \\
\hline
\end{tabular}

Fashion consciousness (Fash), Need for uniqueness (Need), Susceptibility to interpersonal influence (Susc), Collectivism (Coll), Masculinity (Masc) and Adoption (Adop).

\section{Discussion and Conclusion}

The current research is primarily concerned with investigating the influence of certain personality traits on fashion adoption among the youth in Johannesburg. This study concludes that fashion consciousness and the need for uniqueness have a positive influence on fashion adoption, while masculinity/femininity has an inverse relationship with fashion adoption. In other words, the more fashion consciousness an individual is, the more likely that they will adopt a new fashion style. These results are consistent with previous literature (Goldsmith et al. 2015; Lertwannawit \& Mandhachitara, 2012) that indicated a positive relationship between fashion consciousness and fashion adoption. Likewise, the higher an individual's need for uniqueness, the more likely that they will consider adopting a new fashion style. Previous research (McAlister \& Pessemier, 1982; Tian et al., 2001) supports this finding that individuals who desire social distinction tends to be more open to fashion adoption. In contrast to previous literature, the present study found that susceptibility to interpersonal influence do not influence fashion adoption. In other words, it was found that there is no relationship between these two variables. Previous work by several authors (Belleau et al., 2001; Khare \& Rakesh, 2012; Lertwannawit \& Mandhachitara, 2012; Park, Rabolt \& SookJeon, 2006) did indeed indicate a positive relationship between susceptibility to interpersonal influence and fashion adoption. Similarly, collectivism was found to have no relationship with fashion adoption. This finding is contradictory to previous work that confirmed a significant relationship between individualism/collectivism and adoption. In fact, Saad et al. (2015) suggested that individualistic societies are more likely to adopt new fashion style. Lastly, the results for masculinity indicated an inverse relationship with fashion adoption, therefore showing that the more masculine an individual is, the less likely they are to adopt a new fashion style. Therefore inferring that feminine-orientated individuals are more likely to adopt new fashion styles. This is consistent with previous literature by Shephard et al. (2014), which found that feminine-orientated consumers are more likely to adopt new styles. 
Implications of the Study: The contributions of the present study are threefold: firstly, it contributes to theoretical literature in the field of fashion marketing. More specifically, it extends on Sprole's (1980) and Craik's (1995) models of fashion adoption, by confirming that fashion consciousness, the need for uniqueness and masculinity/femininity influence fashion adoption. Secondly, it provides marketing practitioners with insight into factors that influence the youth's intention to adopt a new fashion style. For example, fashion marketers should target their campaigns on fashion conscious consumers. Therefore highlighting fashion forward trends that will attract fashion conscious consumers. Furthermore, fashion marketers should focus on creating campaigns that emphasize uniqueness and individuality. Through the implementation of this strategy, innovators and early adopters will adopt the new trends after which it will, over time, trickle into the commercial market. Marketers should also consider the implications of individualism/collectivism on fashion adoption. For instance, when targeting different cultures, marketers should note that individualistic cultures are more likely to adopt a new fashion trend, therefore, rather invest in less traditional cultures that clearly portray characteristics of individualism. Thirdly, the present study adds to contextual knowledge in the field of fashion adoption among the youth in Johannesburg, an emerging market that is often overlooked in a global context.

Limitations and Future Research: The current research makes several contributions to literature and industry. However it is not without limitations. Firstly, this study is solely conducted on students and possibly to obtain more informed results the researcher would recommend that future studies be conducted on students as well as working people. This would probably provide much needed comparison. There is a possibility that students have restrictions on their buying power hence their responses might have been compromised therefore including employed respondents in such a study would reap different results as to consumers' fashion preferences. Another limitation of the study was that it was a voluntary survey and accuracy of results could have been comprised with students neither having an obligation nor incentive to complete it hence they could have rushed or not read through the survey properly. The other limitation is that the sample might not have had sufficient exposure to fashion and this might have reduced the potential contribution or impact that the study could have made.

\section{References}

Al-Mutawa, F. S. (2013). Consumer-Generated Representations: Muslim Women Recreating Western Luxury Fashion Brand Meaning Through Consumption. Psychology and Marketing, 30(3), 236-246.

Arnould, E. J., Price, L. \& Zinkham, G. M. (2007). Consumers. 2rd Ed. New York: McGraw-Hill.

Bakewell, C., Mitchell, V. W. \& Rothwell, M. (2006). UK Generation Y male fashion consciousness. Journal of Fashion Marketing and Management: An International Journal, 10(2), 169-180.

Balet, C. (2006). Identity, Steidl: Gottingen.

Bearden, W. O., Netemeyer, R. G. \& Teel, J. E. (1989). Measurement of Consumer Susceptibility to Interpersonal Influence. Journal of Consumer Research, 3, 473-481.

Bruner, G. C. \& Hensel, P. J. (1998). Marketing Scales Handbook: A Compilation of Multi-Item Measures Volume II, Chicago, IL: American Marketing Association.

Beaudoin, P., Moore, M. A. \& Goldsmith, R. E. (2000).Fashion Leaders' and Followers' Attitudes toward Buying Domestic and Imported Apparel. Clothing and Textiles Research Journal, 18(1), 56-64.

Belleau, B. D. \& Nowlin, K. (2001). Fashion Leaders' and Followers' Attitudes towards Exotic Leather Apparel Products. Journal of Fashion Marketing and Management: An International Journal, 5(2), 133-144.

Bennett, A. (1999). Subcultures or Neo-tribes? Rethinking the Relationship between Youth, Style and Musical taste. Journal of Sociology, 33, 599-617.

Bowstead, J. M. (2015). Hedi Slimane and the Reinvention of Menswear. Critical Studies in Men's Fashion, 29(1), 23042.

Bucholtz, M. (2002). Youth and Cultural Practice. Annual Review of Anthropology, 31, 525-552.

Cervellon, M., Carey, L. \& Harms, T. (2012). Something Old, Something Used: Determinants of Women's Purchase of Vintage Fashion versus Second-hand Fashion. International Journal of Retail and Distribution Management, 40(12), 956-974.

Chambers, I. (1985). Popular Culture: The Metropolitan Experience. London: Routledge.

Clark, R. A. \& Goldsmith, R. E. (2006). Interpersonal Influence and Consumer innovativeness. International Journal of Consumer Studies, 30(1), 34-43. 
Corrigall, M. (2011). Against the Machine: The Smarteez' (re) fashion post-apartheid Identities. Oxford. Craik, J. The Face of Fashion. New York: Routledge, 1994.

Crask, M. R. \& Reynolds, F. D. (1978). In-depth Profile of Department Store Shopper. Journal of Retailing, 54(2), 23-32.

DeBerry-Spence, B. (2008). Consumer creations of product meaning in the context of African-style clothing. Journal of the Academy of Marketing Science, 36(3), 395-408.

DeLong, M. R. (1998). Theories of Fashion. Retrieved from: http://fashion-history.lovetoknow.com/fashionhistory-eras/theories-fashion

Deutsch, M. \& Gerard, H. B. (1955). A Study of Normative and Informal and Social Influences. The Journal of Abnormal Social Psychology, 52(3), 629-636.

Franzen, M. (2002). The Emergence of a Modern Youth Culture: The Swedish 1930s. Acta Sociologica, 45 (1), 47-56.

Goldsmith, R. \& Reinecke, L. (1992). Identifying Innovators in Consumer Product Markets. European Journal of Marketing, 26(12), 42-55.

Goldsmith, R. E., Moore, M. A. \& Beaudoin, P. (1999). Fashion innovativeness and self-concept: a replication. Journal of Product \& Brand Management, 8(1), 7-18.

Gondola, D. (1999). Dream and Drama: The Search for Elegance among Congolese Youth. African Studies Review, 42, 23-48.

Goulding, C., Shankar, A. \& Elliott, R. (2002). Working Weeks, Rave Weekends: Identity Fragmentation and the Emergence of New Communities. Consumption, Markets and Culture, 5(4), 261-284.

Hebdige, D. (1979). Subculture: The Meaning of Style. New York: Methuen.

Hofstede, G. (1983). National Cultures in Four Dimensions: A Research-Based Theory of Cultural Differences among Nations. International Studies of Management \& Organization, 13, (1/2), Cross- Cultural Management: II. Empirical Studies (Spring - Summer, 1983), pp. 46-74

Hui, H. (1988). Measurement of Individualism-Collectivism. Journal of Research in Personality, 22, 17-36.

Jewsiewicki, B. (2008). Residing in Kinshasa: Between Colonial Modernisation and Globalisation. Research in African Literature, 39(4), 105-119.

Johnson, K. K. P., Lennon, S. J., Casper, C., Damhorst, M. L. \& Lakner, H. B. (2003). An Application of Roger's Innovation Model: Use of Internet to Purchase Apparel, Food, and Home Furnishing Products by Small Community Consumers. Clothing and Textiles Research Journal, 21, 185-196.

Jun, D. G. \& Rhee, E. Y. (2009). The Effects of Fashion Innovativeness and Style-Innovation Attributes of Fashion Adoption. Journal of the Korean Society of Clothing and Textiles, 33(10), 1564-1574.

Lertwannawit, A. \& Mandhachitara, R. (2012). Interpersonal Effects on Fashion Consciousness and Status Consumption Moderated by Materialism in Metropolitan Men. Journal of Business Research, 65(10), 1408-1416

Louchran, K. (2009). The Idea of Africa in European High Fashion: Global dialogues. Journal of Fashion Theory, 13, 243-272.

Keller, C., Magnus, K., Hedrich, S. Nava, P. \& Tochtermann. (2014). Succeeding in Tomorrow's Global Fashion Market. McKinsey \& Company (Retrieved from com/succeeding-in-tomorrows-global-fashionmarket on 17 February 2016)

Khare, A. \& Rakesh, S. (2010). Predictors of Fashion Clothing Involvement Among Indian Youth. Journal of Targeting, Measurement and Analysis for Marketing, 18 (3/4), 209-220.

King, C. W. \& Ring, L. J. (1980). The Dynamics of Style and Taste Adoption and Diffusion: Contributions from Fashion Theory. Advances in Consumer Research, 7, 13-16.

Kjeldgaard, D. \& Askegaard, S. (2006). The Globalisation of Youth Culture: The Global Youth Segment as Structures of Common Difference. Journal of Consumer Research, 33 231-247.

Kjeldgaard, D. (2009). The Meaning of Style? Style Reflexivity among Danish High School Youths. Journal of Consumer Behaviour, 8, 71-83.

Knight, D. K. \& Young Kim, E. (2007). Japanese consumers' need for uniqueness: Effects on brand perceptions and purchase intention. Journal of Fashion Marketing and Management: An International Journal, $11(2), 270-280$.

Lehmann, U. (2000). Tigersprung: Fashion in Modernity. Cambridge: MIT Press

Markus, H. R. \& Kitayama, S. (1991). Culture and the Self: Implications for Cognition, Emotion, and Motivation. Psychological Review, 98(2), 224-253. 
McAlister, L. \& Pessemier, E. (1982). Variety Seeking Behaviour: An Interdisciplinary Review. Journal of Consumer Research, 9 (3), 311-322.

Millan, E., De Pelsmacker, P. \& Wright, L. T. (2013). Clothing consumption in two recent EU Member States: A cross-cultural study. Journal of Business Research, 66(8), 975-982.

Morin, E. (1962). Signalment of VorTid.Kobenhavn: Villadsen\& Christensen.

Nam, J., Hamlin, R., Gam, H. J., Kang, J. H., Kim, J., Kumphai, P., Starr, C. \& Richards, L. (2007). The Fashionconscious Behaviours of Mature Female consumers. International Journal of Consumer Studies, 31(1), 102-108.

Nordas, H. K. (2003). The Impact of Trade Liberalization on Women's Job Opportunities and Earnings in Developing Countries World Trade Review, 2(2), 221-231.

Ostberg, J. (2007). The Linking Value of Subcultural Capital: Constructing the Stockholm Brat Enclave. Consumer Tribes. Oxford: Butterworth-Heinemann.

Park, J. E., Yu, J. \& Zhou, J. X. (2010). Consumer innovativeness and shopping styles. Journal of Consumer Marketing, 27(5), 437-446.

Rahman, S. U., Saleem, S., Akhtar, S., Ali, T. \& Khan, M. A. (2014). Consumers' Adoption of Apparel Fashion: The Role of Innovativeness, Involvement, and Social Values. International Journal of Marketing Studies, $6(3), 49$.

Rogers, E. M. (1995). Diffusions of Innovations, $4^{\text {th }}$ ed. New York: Free Press.

Rogers, E. M. (2005). Diffusion of Innovations, 5th Ed. New York: Free Press.

Roth M. (1995). The effects of culture and socioeconomics on the performance of global brand image strategies. Journal of Marketing Research, 32(2), 163-75.

Saad, G., Cleveland, M. \& Ho, L. (2015). Individualism-collectivism and the quantity versus quality dimensions of individual and group creative performance. Journal of Business Research, 68(3), 578-586.

Shephard, A. J., Kinley, T. R. \& Josiam, B. M. (2014). Fashion leadership, shopping enjoyment, and gender: Hispanic versus, Caucasian consumers' shopping preferences. Journal of Retailing and Consumer Services, 21(3), 277-283.

Simmel, G. (1904). Fashion. International Quarterly, 10, 130-155.

Singh, S. (2006). Cultural differences in, and influences on, consumers' propensity to adopt innovations. International Marketing Review, 23(2), 173-191.

Singh, P. R. (2011). Consumer Culture and Post-modernism, Postmodern Openings, 5(5), 61-86.

Sproles, G. B. (1979). From perfectionism to fadism: Measuring consumers' decision-making styles. University of Arizona

Sproles, G. B. \& Kendall, E. L. (1986). A Methodology for Profiling Consumers Decision making Styles. The Journal of Consumer Affairs, 20(2), 267-279.

Steenkamp, J. E. M. (2001). The Role of National Culture in International Marketing Research. International Marketing Research, 18(1), 30-44.

Thomas, D. (2003). Fashion Matters: La Sape and Vestimentary Codes in Transitional Contexts and Urban Diasporas. $M L N, 118,947-973$.

Tian, K. T., Bearden, W. O. \& Hunter, G. L. (2001). Consumers' need for uniqueness: scale development and validation. Journal of Consumer Research, 28(2), 50-66.

Triandis, H. C. (1991). Review of 'Cultures, Politics, and Research Programs: An International Assessment of Practical Problems in Field Research'. Psycrituques, 36(9), 808.

Wells, W. D. \& Tigert, D. J. (1971). Activities, Interests, and Opinions. Journal of Advertising Research, 11(4), 27-35.

Wilska, T. (2002). Me-A consumer? Consumption, Identities and Lifestyles in Today's Finland. Acta Sociologica, 45(3), 195-210.

Woodhill, B. M. \& Samuels, C. A. (2004). Desirable and Undesirable Androgyny: A Prescription for the TwentyFirst Century. Journal of Gender Studies, 13(1), 15-28.

Ziehe, T. (1992). Cultural Modernity and Individualization. Changed Symbolic Contexts for Young People: Moves in Modernity. Stockholm: Almqvist \& Wiksell International. 